\title{
Individual differences in early language learning: a study of English learners of French
}

Article

Accepted Version

Courtney, L., Graham, S., Tonkyn, A. and Marinis, T. (2017) Individual differences in early language learning: a study of English learners of French. Applied Linguistics, 38 (6). pp. 824-847. ISSN 1477-450X doi:

https://doi.org/10.1093/applin/amv071 Available at https://centaur.reading.ac.uk/45952/

It is advisable to refer to the publisher's version if you intend to cite from the work. See Guidance on citing.

To link to this article DOI: http://dx.doi.org/10.1093/applin/amv071

Publisher: Oxford Journals

All outputs in CentAUR are protected by Intellectual Property Rights law, including copyright law. Copyright and IPR is retained by the creators or other copyright holders. Terms and conditions for use of this material are defined in the End User Agreement.

www.reading.ac.uk/centaur 
Central Archive at the University of Reading

Reading's research outputs online 


\section{Individual differences in early language learning: a study of English learners of French}

\section{Introduction}

Over the last decade there has been a global expansion in the provision of early language teaching (Enever 2011) while in England the government recently took the decision to make learning a foreign language in primary school compulsory from September 2014. In most countries a variety of reasons lie behind the introduction of primary language initiatives. Firstly it is considered as an effective way to generate longterm, and more durable, favourable attitudes to language learning as well as fostering interest in the culture of other nations. With this comes an expectation that early exposure will play an important role in motivating pupils to choose to continue with their language studies at the post-compulsory phase of education. Moreover, the provision of early language programmes worldwide is often based upon the assumption that young instructed learners will find language learning a relatively effortless and straightforward process. This view stems from research based on young naturalistic learners which has found that early exposure to second language learning leads to enhanced proficiency (Muñoz 2012). Yet research across a range of contexts examining early language learning provision, learner outcomes and motivation suggest that young learners in fact exhibit a great deal of variability in terms of attitudes to language learning and second language proficiency. This paper aims to investigate the relationship between individual differences and second language learning outcomes with a view to enhancing our understanding of the variables that can influence individual performance for early language learners in instructed second language contexts.

\section{Individual Differences and Young Learners}

Over many years research has shown that second language (L2) learners can differ vastly in how well and how quickly they learn a second language in both naturalistic and instructed learning contexts. This welldocumented variability in learner attainment is a challenge to both researchers and teachers alike, who wish to understand what individual factors account for the variation observed. As a result, a large field of second language acquisition (SLA) research has developed over recent decades, dedicated to investigating learner differences in a number of areas such as the role of: age, aptitude, affective factors, learner styles and strategies in second language attainment. For the most part, previous studies of individual differences have involved adolescent or adult second language learners. However, the global increase in early language learning has led to an upsurge in the number of studies involving young primary school-aged learners over the last two decades. For example, there have been several large-scale studies aimed at investigating the role of age in instructed second language learning (e.g. Muñoz 2008). Recent reviews of empirical evidence of the role of age (e.g. Lambelet \& Berthele 2015; Muñoz \& Singleton 2011) conclude that the observed benefit of an early start in naturalistic settings cannot necessarily be translated to limited-input foreignlanguage settings. However, the benefits of starting early include the increased duration of learning and more positive learner attitudes. In relation to learner strategies, studies examining young learners' strategies for writing (Griva, Tsakiridou \& Nihoritou 2009) and reading (Samo 2009) found that more competent learners use a wider range of strategies and demonstrate greater 'self-supervision' (Samo 2009:128). More competent young learners take a more global view when reading and writing, taking longer over planning and composition. In contrast less able learners tend to be concerned with local processes such as correct spelling (writing) and the comprehension and selection of lexical items (both reading and writing).

The results of the studies of reading and writing strategies tie in with the proposal that variation in second language learning outcomes may be related to difficulties experienced in 'the most challenging aspect of L1 learning' (Ortega 2009:154), namely the development of literacy. Successive research studies conducted by Sparks, Ganschow and colleagues suggest that first language (L1) literacy skills provide the foundation for successful instructed foreign language learning (Ganschow \& Sparks 1991; Sparks, Pattern, Ganschow, Humbach \& Javorsky 2006). Furthermore, they assert that the native language difficulties that can impact foreign language learning can be recognised in elementary school (in line with Skehan 1989). Ganschow and Sparks (1991) introduced the Linguistic Coding Differences Hypothesis (LCDH) which 
claims that L1 language skills serve as a foundation for learning a foreign language; according to the LCDH, learners have innate differences in their ability to process and use language, and any difficulties with one aspect of language (e.g. phonology/orthography) will negatively impact L1 and L2 development. These assertions support those of Cummins (1979) who developed the Linguistic Interdependence Hypothesis in which first and second languages have common underlying proficiency. Subsequent research by Sparks and colleagues demonstrated that successful second language learners had significantly stronger native language skills in the areas of phonology/orthography and syntax, though not in the area of semantics (e.g. Sparks 2012). Their research has also emphasised the importance of L1 word recognition and decoding in the development of a second language. Those learners with a greater knowledge of grapheme/phoneme correspondences (GPCs) and word recognition achieved higher levels of attainment in the L2, and these elements of L1 reading accounted for $40-55 \%$ of the variance in L2 outcomes. They also argue that learners who experience L1 learning difficulties are also likely to have greater levels of anxiety and lower levels of motivation for second language learning as a result of their previous learning experiences.

The research of Sparks and associates has mainly been undertaken with adolescent Englishspeaking learners of French in the US. Nonetheless, Dufva and Voeten (2001) corroborated their findings in their study of 160 seven-year-old Finnish learners. The results showed that measures of native language literacy (word recognition and comprehension skills), along with phonological memory, significantly predicted second language outcomes and together explained 58\% of the variance between learners. From these results they argue that the more skilled a child is in first language word recognition, the stronger base they will have for mastering L2 GPCs. Dufva and Voeten suggest the key to enabling such children to succeed in L2 learning is to identify at-risk children with a view to enhancing L1 phonological awareness and also providing children with training in foreign language (FL) phonology. Courtney 1 (2014), examining the motivation and linguistic progression of 26 primary school learners of French in England across transition from primary to secondary school, also evaluated the interaction of individual and contextual factors with learner outcomes across different educational phases. The results indicate that L1 (English) literacy levels became increasingly influential for L2 outcomes by the end of the first year of secondary school and interacted with the more literacy-based language pedagogy in secondary school. Whereas oracy activities were prevalent in the primary school setting, the secondary school language lessons focused predominantly on literacy skills which, arguably, favoured those learners with stronger English reading and writing abilities. The disadvantage for learners with low levels of English literacy was further compounded by the fact that no explicit teaching of French GPCs was reported or observed in either phase. No learners, not even those who may have had difficulties with word recognition and decoding in English, received any support in deciphering the sound/symbol links for French which conceivably led to problems with accessing the main source of linguistic input in secondary school: the textbook.

\section{Young learner motivation}

Although the link between L1 literacy abilities and L2 outcomes has been shown to be significant, motivation and willingness to study over a long period of time are also crucial for successful language learning. Indeed one can consider learner motivation as one of the key differences between first and second language acquisition. Much second language motivation research over the last 30 years has been based on Gardner's social psychological model of second language motivation (Gardner 1985). The model contained two principal motivational orientations: 'integrative' which relates to a person's attitudes to the target language and its speakers, and 'instrumental'. Learners who are instrumentally motivated emphasise pragmatic benefits such as those related to work, education, increased social recognition and economic advantage. In the early 1990s Crookes and Schmidt (1991) called for L2 motivation studies to align themselves with more current theories of motivation and those more closely related to educational concerns. In response, there was an increase in research examining the effect of the learning situation on learner motivation in formal educational settings, and international research has shown that the overall learning experience is an important factor in determining learner attitudes and motivation. For example, Nikolov (2009) reports that learners in the study generally held positive attitudes towards learning the L2 and L2 speakers and considered learning the L2 to be important and useful. However, attitudes to the classroom 
experience were more negative with learners citing a lack of challenge and classroom anxiety. Courtney (2014) observed an increasing disconnect between learners' rationale for language study and perceived relevance of classroom activities, leading to a decrease in motivation over time. Wu (2003) and Carreira, Ozaki and Maeda (2013) examined the effect of the learning situation on attitudes to learning English and perceptions of competence; the findings of both studies emphasised the significant role of the teacher in inculcating intrinsic motivation and higher levels of self-confidence. 'Linguistic self-confidence', introduced by Clément (1980), is an important later addition to the Gardnerian perspective of L2 motivation. It concerns a person's belief that they are able to perform in the L2 and achieve their goals, which links to the mainstream psychological notion of 'self-efficacy', referring to a person's beliefs about their abilities to execute a particular task (Bandura 1997). A learner's perceptions and sense of competence will influence their choice of activities in which they will participate, how much effort they expend and how long they are willing to persevere with activities. Indeed, previous research has shown that self-efficacy indices correlate with L2 proficiency (e.g. Clément, Dörnyei \& Noels 1994; Graham 2004).

Studies of young learner motivation, by and large, demonstrate that such learners display more positive attitudes to language learning than have been reported in older learners. In general, primary aged learners are described as enthusiastic, interested and highly motivated (e.g. Cable, Driscoll \& Mitchell 2010). Younger learners are reported to find language lessons inherently enjoyable and interesting, with songs and games frequently liked, as well as creative and interactive activities. Overall, there are few examples cited in the literature of things that younger learners dislike although the dislike of literacy-based activities has been reported (e.g. Courtney 2014). Younger learners often perceive themselves as 'good at languages' but as they grow older their increased language learning experience enables them to make more realistic judgements of their own abilities (Mihaljević Djigunović \& Lopriore 2011). Many see the wider value of learning languages at the primary stage and see a real purpose for communication at home and abroad (Heinzmann 2013).

Notwithstanding the overwhelming positive results mentioned above, studies have also observed a great deal of variability in young learner attitudes and motivation over time, and between different groups of learners, in which some learners do not enjoy lessons and have low perceptions of self-efficacy. For instance, Mihaljević Djigunović and Lopriore (2011) report that at the beginning of their project only $4 \%$ of learners held negative views of language learning whereas this had increased to $12 \%$ by the end of the three year project. In their study of primary languages in England, Cable et al. (2010) reported that Year 3 learners (age 7) held the most favourable views towards learning French with $98.5 \%$ stating they enjoyed the lessons. By Year 6 (age 11) the number had decreased to $74.6 \%$. Some learners considered lessons 'boring' and became frustrated with repeating the same content and making 'baby steps' of progress, a finding which mirrors Erler and Macaro's (2011) assertion that a lack of a sense of progress undermines motivation in early secondary school. Gender is also related to issues of motivation. Several studies have observed gender differences in motivation where girls generally display higher levels than boys across all years (e.g. Stables \& Wikeley 1999; Szpotowicz, Mihaljević Djigunović \& Enever 2009; Tierney \& Gallegi 2011). Heinzmann (2008) also reported higher levels of motivation, positive self-concept, effort and enjoyment in girls.

Furthermore, many studies of early second language learning have found a strong and significant relationship between motivation, and outcomes, with more proficient young learners reporting more positive attitudes to language learning and vice versa (e.g. Courtney 2014; Tragant 2006 ). The direction of causality, however, is often difficult to ascertain. Do learners achieve better results because they are more motivated or are they more motivated because they experience more L2 success? Sparks (2012) posits that learners' previous experience of L1 learning contributes directly to L2 anxiety and low levels of L2 success which in turn leads to lower levels of L2 motivation. Gardner and colleagues by contrast, argue that high levels of L2 motivation lead to higher L2 achievement through positive cycles of motivation-success-motivation. What is clear is that the relationship between affective factors and L2 outcomes is complex and cyclical in nature, and the challenge to educators is to find out how best to develop positive cycles and halt the negative ones.

In summary, previous studies have shown a link between L2 attainment and individual factors such as motivation, L1 literacy and learner gender. Nevertheless, while previous studies have provided essential and much-needed data on the nature of learner differences in early language learning, many have tended to focus on individual factors in isolation and relatively few studies to date have investigated the interaction of 
young learner variables, particularly in relation to different learning settings. One notable exception is a study undertaken by Haenni Hoti, Heinzmann, Müller, Oliveira, Wicki and Werlen (2011) which evaluated the role of L2 listening and reading skills on L3 acquisition. The results show that prior FL experience, L1 literacy and perceptions of self-efficacy influenced L3 listening and reading outcomes. Thus to enhance our current understanding of the role of individual factors in instructed language learning for young, near beginner language learners, the current paper examines the effect of a number of individual learner variables on motivation and learner performance in two oral French tasks and how the individual variables interact, whilst controlling for differences in the learning context.

\section{Methodology}

\section{Research questions}

The present study forms part of a larger investigation into the linguistic development of young learners of French in England which evaluated the effect of teaching approach on learner outcomes (Graham, Courtney, Marinis \&Tonkyn 2014). The current paper focuses on the following research questions:

1. What are the factors that influence motivation, in terms of language attitudes and perceived selfefficacy, in young learners of French and how does this develop over time?

2. To what extent is learners' grammatical and vocabulary development, across Years 5 to 7 , influenced by the interaction of the following individual factors:
a. Gender
b. Learner motivation and perceived self-efficacy
c. Levels of L1 (English) literacy?

\section{Research Design}

\section{Data collection}

The data were collected at five time points, over a two year period (see Table 1). The longitudinal design of the study enabled an evaluation of how the relationship between individual factors and attainment developed over time from primary to secondary school.

\section{Participants}

254 Year 5 learners (penultimate year of primary school, aged 9-10 years), across nine primary schools in the south of England, took part in the first round of data collection. The schools were broadly similar in terms of certain key measures including: the number of children receiving free school meals (an indicator of socioeconomic status), the number of children with English as an additional language and the number of children with special educational needs. All of the learners had experienced at least three years of French teaching in primary school. The data from any child with a French-speaking parent, or with substantial outof-school contact with French speakers, were excluded from the study. As is common in longitudinal studies, there was attrition in learner numbers. The number of participants decreased slightly in Year 6 (final year of primary school) to 243, because of pupil absence and children moving out of the area. There was also some difficulty in tracking learners into Year 7 (first year of secondary school) which led to a further decrease in learner numbers to 165 . The difficulties arose for several reasons. First, the nine primary schools fed into a very large number of secondary schools. Not all secondary schools had a clearly articulated or constant policy regarding the language taught in Year 7, with some switching language between the planning phase and the start of the project. Hence in some cases project learners were no longer learning French in Year 7 and thus could not be tracked further. In a small number of cases we were informed that learners had been withdrawn from language classes, a practice that occurs fairly frequently in schools in England (Board \& Tinsley 2014), especially among learners with low levels of English literacy. 
$<$ Table 1 near here>

\section{Data collection instruments}

Two French assessment tasks were administered to all learners at sessions 1, 2 and 4: a sentence repetition task (SR) and a photo description task (PD). Both tasks focused on productive oracy skills as some of the learners would have had little exposure to the written form in French, although all of the learners had French oracy experience. To ensure the content validity of the language assessment tasks a variety of primary French schemes of work and resources were consulted along with the views of primary French teachers. Sentence repetition (or elicited imitation) tasks have been widely used in first and second language acquisition research and can be used to assess knowledge of, for example, target language phonology, morphology, syntax and lexis (e.g. Tracy-Ventura, McManus, Norris \& Ortega 2014). They have also been used in speech and language therapy settings to identify children with specific language impairment (see Riches, Loucas, Baird, Charman \& Simonoff 2010 for a review). It is argued that learners can only accurately repeat sentences they hear if they have acquired the necessary grammatical features (Lust, Flynn \& Foley, 1996), and, therefore, it is claimed that this method provides a window into underlying implicit linguistic knowledge (Erlam 2006). Three clear advantages of using SR tasks are that they are quick to administer, easy-to-score and are not literacy-dependent, which is especially valuable when studying young language learners in the early stages of language learning.

For the SR task in the current study the learners had to listen to a series of 18 sentences of varying lengths and then repeat them verbatim. For examples of the SR task sentences, see Appendix A. The sentences were rigorously designed to ensure they were long enough (7-10 syllables) to tax the children's processing ability, based upon Chiat, Armon-Lotem, Marinis, Polišenská, Roy \& Seeff-Gabriel (2013). As a result the learners had to reconstruct the meaning and grammar of the sentences rather than being able to simply repeat the sentence. As the learners heard the sentence they were also shown an image of the objects referred to in the sentence to encourage them to focus on meaning. Two sequences of sentences were produced and delivered on a random basis to counteract any possible order or fatigue effects. Sentences focused on nineteen lexical items and three grammatical features with eight items per feature: article-noun agreement (gender), adjective-noun agreement (gender) and simple present tense $3^{\text {rd }}$ person subject-verb agreement. The PD task was designed to elicit seventeen lexical items and the same three grammatical features, although it contained only six items per feature (see appendix B). Therefore both tasks aimed to measure general proficiency with a focus on lexical and grammatical knowledge. A score was given for the correct production of each target lexical item and one point was awarded for correct art+noun agreement; correct adj+noun agreement; correct art+adj agreement and correct subj+verb agreement. The tasks were scored by Courtney in all three rounds and Graham scored $10 \%$ of data in each round. An inter-rater reliability rate of $98 \%$ was achieved, with differences in scores resolved through discussion.

To take account of the age of the participants and the time constraints, the attitude and motivation questionnaire was limited to 19 items with a four-point Likert scale response format (Likert 1932) and two sentence completion items (see Appendix C). For further details of the questionnaire design see Graham (under review). Items were grouped into three components: attitudes to learning French (6 items), Current Self-efficacy ( 8 items) and Future Self-efficacy (5 items). Attitudes to learning French included how much learners enjoyed French lessons and their perceptions of the importance of learning French. It was considered essential to measure learners' perceptions of self-efficacy in detail with the aim of understanding what learners consider they were good at and those aspects of language learning they perceived as difficult. Therefore, the questionnaire included items for present and future self-efficacy related to both oracy- and literacy-based language learning activities in order to provide insights into which areas of French were approached by learners with most or least confidence.

The Year 5 primary school class teachers also provided scores for all learners for both English reading and writing, based on their National Curriculum levels. In England at the time of the study, learners were assessed in all curriculum subjects through so-called levels and sub-levels from 1-8. For the study, sublevels were converted to a point scale from 1 (1a) to 13 (5a). Scores for reading and writing were combined to give an overall L1 (English) literacy score out of a possible 13. The English literacy scores were 
standardised in SPSS $®$ and two learners (one male, one female) were excluded from the analysis as their English literacy scores were greater than three standard deviations below the mean. The schools did not indicate any specific learning difficulties within the participants. Furthermore, the one pupil who was noted as having English as an additional language had English literacy scores within the average range.

\section{Results}

1. What are the factors that influence motivation, in terms of language attitudes and perceived selfefficacy, in young learners of French and how does this develop over time?

After each administration of the questionnaire the item scores were entered into SPSS ${ }^{\circ}$ for statistical analysis. Cronbach Alpha coefficients were calculated to test the validity and reliability of the motivation scales employed. These are shown in Table 2 along with the scale mean scores, standard deviations, range and percentage of learners scoring two or below (a negative response).

$<$ Table 2 near here>

As seen in previous studies of young learners, the mean scores for the entire cohort in Year 6 indicate that in general the learners held positive attitudes to learning French in primary school and considered language learning enjoyable and useful. Within these positive group means, however, lies a good deal of individual variation, especially at the end of primary school. A significant proportion (19\%) of learners claimed they did not enjoy learning French, 34.6\% held negative perceptions of their current ability in French, and 22.5\% lacked confidence in their future abilities. Furthermore, a series of Spearman Rank Order correlations show moderate but significant correlations between Self-efficacy (combination of both current and future selfefficacy) and enjoyment of language lessons in Year 6 and $7\left(\mathrm{Y}^{6} \mathrm{r}^{\mathrm{s}}=.451^{* *}, \mathrm{Y} 7(1) \mathrm{r}^{\mathrm{s}}=.562^{* *}, \mathrm{Y} 7(2)=\right.$ $\mathrm{r}^{\mathrm{s}} .522 * * ; * *$ indicates $\mathrm{p}=.01$ or below throughout).

While correlational data provide a useful insight into the influence of a range of variables, they do not necessarily reflect the complex interplay that is likely to exist between different factors. Therefore, to evaluate the factors that influence both language attitudes and self-efficacy in Year 6 and Year 7, more sophisticated statistical analysis was employed incorporating a series of multiple regression analyses using SPSS. The individual variables of gender and L1 literacy were included in the regression models as was the School variable in order to account for the factors related to different learning contexts (such as teaching time and teacher expertise), since these variables have been shown to be related to learner motivation and outcomes (Graham et al. 2014). All variables were assessed for collinearity and all had a correlation coefficient of <.3. All of the variables were entered into the models simultaneously via the Enter method in SPSS. Dummy variables for schools (1 to 9) were created based upon a comparison with School 1, the highest performing school.

The results in Table 3 show that gender, L1 literacy and school factors had no significant effect on variation in attitudes to learning languages in Year 6. At the beginning of Year 7, however, gender effects did become significant. Indeed the motivation data shows that girls displayed significantly higher levels of enjoyment than boys at the beginning of Year $7(\mathrm{z}=-2.439, \mathrm{p}=.02)$. Nevertheless, the gender effect disappeared as school-related factors became more prominent by the end of Year 7, explaining 37\% of the variance in language attitudes.

$<$ Table 3 near here>

Although, in general, girls displayed higher levels of self-efficacy than boys, the results in Table 4 show that gender does not have a significant effect on levels of self-efficacy when L1 literacy and school factors are also considered. Indeed, L1 literacy and school effects explain 52\%-56\% of the variance in self-efficacy levels in Year 6 and at the beginning of Year 7 and L1 literacy alone explained 50\% of the variance in perceptions of self-efficacy by the end of Year 7. 
In order to explore in more detail the nature of the influence of L1 on learner motivation, the cohort of learners were categorised into three groups based on their L1 literacy level: High, Mid and Low. Learners who had an English literacy score greater than one standard deviation above the mean were placed in the High group. The Low group included those learners with a literacy score of less than one standard deviation below the mean; the Mid group included those with scores falling within one standard deviation above or below the mean. Table 5 shows that learners with high English literacy levels in general held more positive attitudes to language learning than the other two groups (although Mid-level learners were most positive at the end of Year 7). However it is in levels of learners' perceptions of self-efficacy that the significant differences are seen. Learners with high L1 literacy levels were by and large significantly more confident in their French ability across Years 6-7 than Mid or Low L1 literacy level learners (Mann-Whitney U Test). In addition, examining changes in self-efficacy over time using Friedman's tests for repeated measures, levels for High and Mid learners increased significantly $(\chi=11.66, p<.001 ; \chi=32.52, p<.001$ respectively), whereas for the Low learners the differences were not significant $(\chi=1.75, p=.417)$. An analysis of individual question responses in Year 6 shows that learners with Low levels of English literacy had significantly lower levels of self-confidence in writing sentences in French, spelling in French and their knowledge of word order and gender assignment. At the start of Year 7, while the cohort as a whole increased its level of selfefficacy, those with Low L1 literacy levels still had a mean score of less than two for understanding the teacher and reading in French, although scores did increase significantly for writing sentences in French. Nonetheless, this is in contrast to Mid learners, whose self-efficacy scores increased significantly across all areas.

$<$ Table 5 near here>

2. To what extent is learners' grammatical and vocabulary development, across Years 5 to 7 , influenced by the interaction of the following individual factors:
a. Gender
b. Learner motivation and perceived self-efficacy
c. Levels of L1 (English) literacy

The mean scores for the cohort as a whole on the Sentence Repetition and Photo Description task are shown in Table 6. Overall, learners demonstrated steady and significant progress between Year 5 and 7 in both the SR task ( $\mathrm{t}$-test, $\mathrm{t}=13.69, \mathrm{df}=163, \mathrm{p}<.001)$ and the $\mathrm{PD}$ task (t-test, $\mathrm{t}=11.28, \mathrm{df}=163, \mathrm{p}<.001)$. Nonetheless, with a possible maximum score of 56 for the SR task ( 28 for grammar and 28 for vocabulary) and 54 for the PT task (30 for grammar and 24 for vocabulary), it is clear that, in general, the learners found both tasks challenging. Even though the learners generally found the PD task more difficult, the correlation between mean scores of the two tasks was strong and highly significant across all time points (Y5 $\mathrm{r}=.666^{* *}, \mathrm{Y} 6$ $\left.\mathrm{r}=.707^{* *}, \mathrm{Y} 7 \mathrm{r}=.742^{* *}\right)$. As with the motivation data, there was a great deal of variation in learner outcomes for both tasks, with some learners performing at near ceiling level (particularly in Year 7) while others maintained very low scores even in Year 7.

\section{$<$ Table 6 near here>}

Firstly, in order to explore the reasons for this high degree of variation, a series of Spearman Rank Order correlations was calculated on those individual variables that previous research has shown to be predictors of second language outcomes: gender, L1 literacy level, Attitudes to learning French and Self-efficacy. Table 7 shows that there was a small but significant association between learner gender and task results and a significant, moderate link between self-efficacy and outcomes. On the other hand, attitudes to learning French were not correlated significantly with Year 6 outcomes, but did reach significant levels in Year 7 . It is, however, apparent that the strongest relationship was between level of L1 literacy and second language 
attainment, mirroring the findings of previous studies of secondary school learners (e.g. Sparks et al. 2006) and of young learners (Courtney 2014).

$<$ Table 7 near here $>$

The strength of this relationship is also apparent from the differences in scores for learners in the three L1 literacy groups (Table 8), with the High literacy group gaining the highest scores, and the Low literacy group the lowest, for both tasks and all time points. Furthermore, the gap between these groups widened across the three time points, whereas the gap between the Mid and High group remained relatively constant from Year 6 to Year 7.

$<$ Table 8 near here>

A repeated measures ANOVA was conducted with Bonferroni post-hoc tests. The difference between the three groups was highly significant across all time points for both the SR and PD tasks (Table 9).

$<$ Table 9 near here>

Interestingly, girls significantly outperformed boys in the language assessments in all three rounds. At the same time, however, the mean L1 literacy score for the girls (9.14, s.d.1.74) was significantly higher than for the boys $(8.13$, s.d. $1.85 ; \mathrm{t}=4.476, \mathrm{p}<.001)$. Indeed when L1 literacy was controlled for by using ANCOVA, the differences between girls and boys on the French task scores became non-significant for both tasks in all rounds except for the PD task in Year $5(\mathrm{f}(1,1)=7.383, \mathrm{p}=.007)$. Moreover, those boys with high L1 literacy levels performed well on both tasks across the three rounds and maintained positive attitudes to learning French and perceptions of self-efficacy.

Again, to explore the interrelationship of the different factors, the individual variables of Gender, L1 literacy, Attitudes to learning French and Self-efficacy were included in a series of regression models, although motivation data were not collected in Y5 so were not included in the model for the Year 5 task scores. The School variable was included to allow for a more reliable evaluation of the role of individual variables, by controlling for variation in hours and type of exposure to the L2. All variables were assessed for collinearity and all had a correlation coefficient of <.3, except L1 Literacy and Self-efficacy which had a significant but small correlation of $.327 * *$ in Year 6 and $.353 * *$ in Year 7 . All of the variables were entered into the models simultaneously via the Enter method in SPSS.

The results displayed in Table 10 show that for the sentence repetition task the models explain around $46-61 \%$ of the variance in task results across Years 5 to 7 . L1 literacy is the most influential explanatory factor, followed by school-related differences, then Self-efficacy, whereas Gender and Attitudes to learning French do not appear to have any significant influence on SR task scores.

$<$ Table 10 near here $>$

The regression analyses for the PD task produced similar results (see Table 11) with the regression models explaining 53-59\% of the variance in task results. To ascertain the extent of the influence of L1 literacy on outcomes, a series of regression analyses was conducted with only L1 literacy included in the model. For both tasks, L1 literacy alone accounted for 35-38\% of variance in the PD task outcomes and 29-39\% in the SR task results across the three rounds. This is comparable to the results seen in previous studies (e.g. Dufva \& Voeten 2001; Sparks et al. 2006).

$<$ Table 11 near here> 


\section{Discussion}

The findings of the current study clearly demonstrate the significant role that individual differences play even at the very earliest stages of language learning. The motivation and self-efficacy mean scores for the study cohort as a whole show that, generally speaking, learners held positive views towards learning French in primary school. However, from the range of learner responses it is clear that the widely held view that all young learners enjoy learning languages is unsupported. A significant proportion of the young learners in this study held negative views towards their primary language lessons and negative perceptions of their own current and future abilities in French at the end of primary school. For the most part, however, enjoyment of French lessons increased in secondary school and learners' self-perceptions became more positive. Nevertheless, for some, negative perceptions of their French abilities decreased further by the end of the first year of secondary school, especially in relation to French literacy skills. Furthermore, the results of the language assessment tasks contradict the widely held view that language learning is easy for all younger learners. While it is true that overall the learners made small but significant progress over the two years, and some learners performed very well on both tasks, there was a wide variation in learner outcomes across all years. It is clear that some learners found the tasks extremely challenging in year 5, and indeed made very little progress over the course of the study.

Even though a series of regression analyses demonstrated that L1 literacy levels accounted for 29$39 \%$ of the variation seen in the French task scores, echoing the findings of previous studies (e.g. Sparks et al. 2006), it is clear that there is a complex and cyclical relationship between L1 literacy skills, self-efficacy and attainment. Learners with lower levels of French attainment found lessons less enjoyable than their peers and also had lower levels of self-efficacy, but we do not know if this was the case when they began to learn French, two to three years prior to the start of our study. It is possible that these learners would have displayed attitudes comparable with those of their peers at the initial stages of language learning, but that their language learning experience over the course of 3-4 years may have led to a decrease in enjoyment and more negative selfperceptions. While general attitudes to language learning were not strongly related to outcomes, self-efficacy was more strongly correlated with task scores at all time points. For older language learners self-efficacy has been strongly linked with achievement and is argued to have considerable impact on levels of persistence (e.g. Erler \& Macaro 2011); likewise, within expectancy-value models of motivation (Eccles, 1983) learners' expectations of success and the value they place on this success are held to influence learner motivation. Given that the stated aim of early language learning in England is to lay the foundation for future language learning in terms of motivation and outcomes, the present study raises issues of concern, if some young learners are already displaying low levels of self-efficacy and lack of progress even before they reach secondary school. One limitation of the study is that our measure of L1 literacy relied on teacher assessment of learners' skills broadly conceived. To gain a fuller insight into the role of L1 literacy in instructed language learning, further studies should seek more fine-grained measures of latent cognitive abilities such as decoding and phonological awareness. In addition, we measured French attainment through oral performance only. One would expect even stronger correlations between L1 literacy levels and performance on literacy-based L2 tasks and this is an area that requires further investigation, particularly with young learners.

The challenge is to ensure all learners feel they are making progress and are able to achieve. This needs to be tackled head-on to ensure that all learners enter secondary school equipped with positive attitudes and the tools to be successful. If not, the danger is that rather than promoting positive attitudes, early language teaching may actually lead many young learners to become demotivated and disillusioned sooner, and therefore unwilling and unable to continue with their language learning, trapped in a negative cycle of demotivation, diminished self-confidence and poor performance. It is important to state that these findings regarding individual differences should not be taken as deterministic, or used to justify the removal of certain learners from foreign language study. In a survey of language provision in England, Board and Tinsley (2014) report that approximately $27 \%$ of secondary schools surveyed withdraw learners from language study on the grounds that they are of 'lower ability' (p.6) and need to spend more time on numeracy and English literacy. While such disapplication is much less common in primary school, the gap between French language outcomes in our study for learners with low and high levels of English literacy suggests that teachers in both school sectors lack awareness of the issues facing learners with lower L1 literacy levels. In 
particular, work is needed to help schools to devise and adopt teaching practices and interventions to ensure all learners are capable of some level of success. For example, the introduction of the systematic teaching of L2 GPCs in primary school and its continuation into secondary school would be helpful for all learners and those with low L1 literacy levels in particular. An intervention study by Ganschow and Sparks (1995) that involved the direct instruction of Spanish GPCs to learners with L1 literacy difficulties found that 'at-risk' learners made significant gains in both L1 and L2 attainment. Furthermore, it may be the case that teachers and curriculum designers need to make accommodations in order to meet the needs of all learners. This might be achieved through a more equal balance between oracy and literacy activities and through greater differentiation in language lessons. Further practical examples are offered by Ganschow et al. (1998) such as allowing more time for test taking and making allowances for spelling mistakes for learners with literacy difficulties.

The current study makes an important contribution to our understanding of the nature of individual differences in young learners and in particular of the role of first language literacy in second language attainment and attitudes. The inclusion of a number of learner variables and an analysis of how they interact provides richer and more detailed information about early language learning than has been found in previous studies, information which can be used to avoid overly-simplistic assumptions. For example, in line with previous studies, girls displayed higher levels of enjoyment and self-efficacy across all time points. Additionally, the difference between girls and boys widened to significant levels in secondary school, particularly in the learners' perceptions of their ability to write in French. Given the significant role of L1 literacy in L2 outcomes, it is entirely possible that the findings related to gender differences are linked to those given in the UK National Literacy Trust (2012) report into boys' achievement in L1 reading: 'boys' attitudes towards reading and writing, the amount of time they spend reading and their achievement in literacy are all poorer than those of girls' (p.4). Therefore, further nuanced and sophisticated studies of gendered attitudes to and motivation for language learning are required, as the results suggest that affective factors are likely to be mediated by learners' first language abilities and prior learning experience, and not only related to course content and the predominance of female teaching staff in language classrooms.

\section{References}

Bandura, A. 1997. Self-efficacy: The Exercise of Control. W.H. Freeman. Board, K. and T. Tinsley. 2014. Language Trends 2013/14: The State of Language Learning in Primary and Secondary Schools in England. CfBT Education Trust Publications.

Cable, C. P. Driscoll and R. Mitchell. 2010 Languages Learning at Key Stage 2: A Longitudinal Study. DCSF

Chiat, S., Armon-Lotem, S., Marinis, T., Polišenská, K., Roy, P. and Seeff-Gabriel, B. (2013)

Assessment of language abilities in sequential bilingual children: the potential of sentence imitation tasks. In: Gathercole, V. C. M. (ed.) Issues in the Assessment of Bilinguals. Multilingual Matters, Bristol, pp. 56-86.

Clément, R. 1980. 'Ethnicity, contact and communicative competence in a second language' in Giles, H., W.P. Robinson and P.M. Smith (eds.): Language: Social Psychological Perspectives). Pergamon.

Clément, R., Z. Dörnyei and K. Noels1994. 'Motivation, self-confidence and group cohesion in the foreign language classroom'. Language Learning, 44/3:417-448.

Courtney, L. 2014. Moving from primary to secondary education: An investigation into the effect of primary to secondary transition on motivation for language learning and foreign language proficiency. University of Southampton.

Crookes, G. and R.W. Schmidt. 1991. 'Motivation: Reopening the research agenda'. Language Learning, 41/4:469-512.

Cummins, J. 1979. 'Cognitive/academic language proficiency, linguistic interdependence, the optimum age question and some other matters'. Working Papers on Bilingualism, 19: 121-129.

Dufva, M. and M. Voeten.2001. 'Native language literacy and phonological memory as prerequisites for learning English as a foreign language'. Applied Psycholinguistics, 20: 329-348. 
Eccles, J. 1983. 'Expectancies, values and academic behaviours'. In Spence, J.T. (ed.): Achievement and Achievement Motives. W.H. Freeman and Co.

Enever, J. (ed.) 2011. ELLiE: Early Language Learning in Europe. British Council.

Erler, L. and E. Macaro.2011. 'Decoding ability in French as a foreign language and language learning motivation’. The Modern Language Journal, 95/4, 496-518.

Erlam, R. 2006. 'Elicited imitation as a measure of L2 implicit knowledge: An empirical validation study'. Applied Linguistics, 27: 464-491.

Ganschow, L. and R. Sparks. 1991. 'A screening instrument for the identification of foreign language learning problems'. Foreign Language Annals, 24: 383-397.

Ganschow, L. and R. Sparks. 1995. 'Effects of direct instruction in Spanish phonology on the native language skills and foreign language aptitude of at-risk foreign language learners'. Journal of Learning Disabilities, 28: 107-120.

Ganschow, L., R. Sparks and R. Javorsky. 1998. 'Foreign language learning difficulties: An historical perspective.' Journal of Learning Disabilities, 31/3: 248-258.

Gardner, R. 1985. Social Psychology and Second Language Learning: The Role of Attitudes and Motivation. Edward Arnold.

Graham, S. 2004. Giving up on modern foreign languages? Students' perceptions of learning

French. Modern Language Journal, 88 (2). pp. 171-191.

Graham, S., Courtney, L., Marinis, T. and Tonkyn, A. (2014) Primary Modern Languages: the impact of teaching approaches on attainment and preparedness for secondary school language learning. Project Report. University of Reading (Unpublished).

Griva, E., H. Tsakiridou and I. Nihoritou. 2009. 'A study of FL Composing Process and Writing Strategies Employed by Young Learners' in Nikolov, M. (ed.): Early Learning of Modern Foreign Languages: Processes and Outcomes. Multilingual Matters.

Haenni Hoti A.U., Heinzmann, S., Müller, M., Oliveira, M., Wicki, W. and Werlen, E. 2011. Introducing a second foreign language in Swiss primary schools: the effect of L2 listening and reading skills on L3 acquisition. International Journal of Multilingualism, 8/2: 98-116

Heinzmann, S. 2008. Girls are better at language learning than boys: Do stereotypic beliefs about language learning contribute to girls' higher motivation to learn English in primary school? Bulletin VALS-ASLA, 89: 19-36

Heinzmann, S. 2013. Young Language Learners' Motivation and Attitudes: Longitudinal, comparative and explanatory perspectives. Continuum.

Likert, R. 1932. 'A technique for the measurement of attitudes'. Archives of Psychology, 140.

Lust, B., S. Flynn and C. Foley. 1996. 'What children know about what they say: Elicited imitation as a research method for assessing children's syntax' in McDaniel, D., C. McKee and H. Smith Cairns (eds.): Methods for Assessing Children's Syntax. MIT Press

Matsuzaki Carreira, J., Ozaki, K and Maeda, T. 2013. 'Motivational Model of English learning among elementary school students in Japan'. System, 41 : 706-719.

Mihaljević Djigunović, J. and L. Lopriore. 2011. 'The learner: do individual differences matter?' in Enever, J. (ed.) ELLiE: Early Language Learning in Europe. British Council.

Muñoz, C. 2008. 'Symmetries and asymmetries of age effects in naturalistic and instructed L2 learning'. Applied Linguistics, 24/4: 578-596

Muñoz, C. 2012. Intensive Exposure Experiences in Second Language Learning. Multilingual Matters.

Muñoz, C. and D. Singleton. 2011. 'A critical review of age-related research on L2 ultimate attainment'. Language Teaching, 44/1: 1-35.

Nikolov, M. 2009. Early Modern Foreign Language Programmes and Outcomes: Factors Contributing to Hungarian Learners' Proficiency in in Nikolov, M. (ed.): Early Learning of Modern Foreign Languages: Processes and Outcomes. Multilingual Matters.

Ortega, L. 2009. Understanding Second Language Acquisition. Hodder.

Pinter, A. 2011. Children Learning Second Languages. Palgrave Macmillan. 
Riches, N.G., T. Loucas, .G. Baird, T. Charman and E. Simonoff. 2011. 'Non-word repetition in adolescents with Specific Language Impairment and Autism plus Language Impairments: a qualitative analysis'. Journal of Communication Disorders, 44/1: 23-36.

Samo, R. 2009. 'The Age Factor and L2 Reading Strategies' in Nikolov, M. (ed.): Early Learning of Modern Foreign Languages: Processes and Outcomes. Multilingual Matters.

Skehan, P. 1989. Individual Differences in Second Language Learning. Edward Arnold.

Sparks, R. L. 2012. 'Individual differences in L2 learning and long-term L1-L2 relationships' in Roberts, L. and A. Meyer (eds.): Individual Differences in Second Language Learning. Wiley.

Sparks, R., J. Patton, L. Ganschow, N. Humbach, N. and J. Javorksy. 2006. 'Native language predictors of foreign language proficiency and foreign language aptitude'. Annals of Dyslexia, 56: 129-160.

Szpotowicz, M., J. Mihaljević Djigunović and J. Enever. 2009. 'Early language learning in Europe : a multinational, longitudinal study', in Enver, J., J. Moon and U. Raman (eds.) : Young Learner English Language Policy and Implementation : International Perspectives. Garnet Publishing.

Stables, A. and F. Wikeley. 1999. 'From bad to worse? Pupils' attitudes to modern foreign languages at ages 14 and 15'. Language Learning Journal, 20: 27-31.

Tierny, D. and L, Gallastegi. 2011. 'The attitudes of the pupils towards modern languages in the primary school (MLPS) in Scotland'. Education 3-13, International Journal of Primary, Elementary and Early Years Education, 39/5, 483-498.

Tracy-Ventura, N., K. McManus, L. Ortega and J. Norris. 2014. 'Repeat as much as you can: elicited imitation as a measure of global proficiency in French L2' in Leclercq, P., A. Emonds and H. Hilton (eds.) Proficiency Assessment Issues in SLA research: Measures and Practices. Multilingual Matters.

Tragant, E. (2006). 'Language learning motivation and age' in C. Munoz (Ed.), Age and the rate of foreign language learning. Multilingual Matters.

UK National Literacy Trust. 2012. Boys' Reading Commission: The report of the All-Party Parliamentary Literacy Group Commission. National Literacy Trust Publications.

Wu, X. (2003). 'Intrinsic motivation and young language learners: the impact of the classroom environment'. System, 31, 501-517.

Table 1: Data collection schedule

\begin{tabular}{llll}
\hline Session & School Year & Date & Instrument \\
\hline 1 & 5 & June/July 2012 & French assessments \\
2 & 6 & Jan-Mar 2013 & French assessments \\
3 & 6 & June/July 2013 & Motivation questionnaire \\
4 & 7 & Oct-Dec 2013 & French assessments \\
& & & Motivation Questionnaire \\
5 & 7 & June 2014 & Motivation Questionnaire \\
\hline
\end{tabular}


Table 2: Responses to the motivation questionnaire for the main scales.

\begin{tabular}{cccccc}
\hline Scale & Year & $\begin{array}{c}\text { Mean \& } \\
\text { s.d. }\end{array}$ & Range & $\begin{array}{c}\text { \% learners } \\
\text { scoring 2 or less }\end{array}$ & $\begin{array}{c}\text { Alpha } \\
\text { Coefficient }\end{array}$ \\
\hline Attitudes to & 6 & $2.60(.57)$ & $1.17-4.0$ & $19 \%$ & .82 \\
learning & $7(1)$ & $3.07(.46)$ & $1.71-4.0$ & $3.1 \%$ & .83 \\
French & $7(2)$ & $2.97(.62)$ & $1.0-4.0$ & $9.1 \%$ & .86 \\
\hline Current & 6 & $2.41(.66)$ & $1.0-3.75$ & $34.6 \%$ & .85 \\
Self-efficacy & $7(1)$ & $2.65(.58)$ & $1.0-3.88$ & $15.6 \%$ & .81 \\
& $7(2)$ & $2.95(.63)$ & $1.0-4.0$ & $10.1 \%$ & .88 \\
\hline Future & 6 & $2.51(.61)$ & $1.0-4.0$ & $22.5 \%$ & .81 \\
Self-efficacy & $7(1)$ & $2.86(.50)$ & $1.0-4.0$ & $7.5 \%$ & .83 \\
& $7(2)$ & $3.01(.59)$ & $1.0-4.0$ & $8.1 \%$ & \\
\hline
\end{tabular}

Table 3: General linear regression models for Attitudes to Learning French Years 6 and 7

\begin{tabular}{|c|c|c|c|c|c|c|c|c|c|c|c|c|}
\hline Variable & \multicolumn{4}{|c|}{ Attitudes to Learning French Year 6} & \multicolumn{4}{|c|}{ Attitudes to Learning French Year 7(1) } & \multicolumn{4}{|c|}{ Attitudes to Learning French Year 7(2) } \\
\hline L1 Literacy & .013 & .023 & .043 & .563 & .032 & .022 & .124 & 1.443 & .001 & .039 & .003 & .028 \\
\hline SchlvsSch2 & .132 & .155 & .074 & .849 & .015 & .137 & .012 & .108 & .335 & .208 & -.214 & -1.613 \\
\hline SchlvsSch3 & .157 & .138 & .109 & 1.138 & .006 & .126 & .006 & .048 & .479 & .181 & -.379 & $-2.650 * *$ \\
\hline SchlvsSch6 & -.019 & .158 & -.011 & -.122 & .107 & .283 & .032 & .378 & - & - & - & - \\
\hline SchlvsSch7 & -.140 & .159 & -.076 & -.877 & .077 & .159 & .049 & .482 & -.517 & .221 & -.301 & $2.339 *$ \\
\hline SchlvsSch8 & -.016 & .161 & -.009 & -.102 & .007 & .157 & .005 & .045 & -.781 & .237 & -.414 & $-3.303 * *$ \\
\hline Model F statistic & 1.100 & & & & 1.790 & & & & $2.414 *$ & & & \\
\hline
\end{tabular}

Table 4: General linear regression models for Perceptions of Self-Efficacy Years 6 and 7

\begin{tabular}{|c|c|c|c|c|c|c|c|c|c|c|c|c|}
\hline Variable & \multicolumn{4}{|c|}{ Self-Efficacy Year 6} & \multicolumn{4}{|c|}{ Self-Efficacy Year $7(1)$} & \multicolumn{4}{|c|}{ Self-Efficacy Year 7(2) } \\
\hline L1 Literacy & .080 & .022 & .247 & $3.732 * *$ & .064 & .023 & .218 & $2.762^{* * *}$ & .117 & .034 & .358 & 3.477 *** \\
\hline Sch1vsSch2 & .285 & .143 & .152 & $1.997 *$ & .245 & .135 & .182 & 1.818 & .126 & .179 & .087 & .703 \\
\hline SchlvsSch3 & .147 & .127 & .097 & 1.162 & .137 & .124 & .119 & 1.105 & -.121 & .156 & -.104 & -.776 \\
\hline Sch1vsSch5 & -.191 & .174 & -.076 & -1.101 & -.167 & .170 & -.083 & -.985 & - & - & - & - \\
\hline Sch1vsSch6 & .395 & .146 & .207 & $2.703 * *$ & .549 & .278 & .146 & $1.980^{*}$ & - & - & - & - \\
\hline SchlvsSch7 & .345 & .147 & .177 & $2.349 *$ & .326 & .156 & .186 & $2.091 *$ & -.261 & .190 & -.165 & -1.372 \\
\hline Sch1vsSch8 & .002 & .149 & .001 & .011 & -.162 & .155 & -.097 & -1.046 & -.345 & .204 & -.198 & -1.692 \\
\hline Model F statistic & $8.345^{* * *}$ & & & & $6.683^{* * *}$ & & & & $5.007 * *$ & & & \\
\hline
\end{tabular}


Table 5: mean scores for attitudes to learning French and self-efficacy by L1 literacy level with results of Mann-Whitney U tests

\begin{tabular}{|c|c|c|c|c|}
\hline Year & $\begin{array}{c}\text { L1 Literacy } \\
\text { Level }\end{array}$ & $\begin{array}{c}\text { Attitudes to learning } \\
\text { French }\end{array}$ & $\begin{array}{c}\text { Current } \\
\text { Self-efficacy }\end{array}$ & $\begin{array}{c}\text { Future } \\
\text { Self-efficacy }\end{array}$ \\
\hline \multirow[t]{6}{*}{6} & Low & 2.48 & 1.94 & 2.09 \\
\hline & $n=26$ & (s.d. $=.63$ ) & (s.d. $=.55$ ) & (s.d.=.61) \\
\hline & Mid & 2.61 & $2.43 * * \uparrow$ & $2.52 * * \uparrow$ \\
\hline & $\mathrm{n}=157$ & (s.d. $=.57)$ & (s.d. $=.65$ ) & (s.d. $=.60)$ \\
\hline & High & 2.66 & 2.57 & 2.71 \\
\hline & $\mathrm{n}=48$ & $($ s.d. $=.57)$ & (s.d.=.63) & (s.d. $=.57)$ \\
\hline \multirow[t]{6}{*}{$7(1)$} & Low & 2.85 & 2.20 & 2.45 \\
\hline & $\mathrm{n}=14$ & $(\mathrm{~s} . \mathrm{d} .=.51)$ & (s.d. $=.47)$ & (s.d. $=.41$ ) \\
\hline & Mid & 3.08 & $2.64 * * \uparrow$ & $2.85 * * \uparrow$ \\
\hline & $\mathrm{n}=110$ & (.46) & (s.d. $=.57)$ & (s.d. $=.51)$ \\
\hline & High & 3.14 & $2.87 * \uparrow$ & $3.07 * \uparrow$ \\
\hline & $\mathrm{n}=36$ & (.41) & (s.d. $=.54)$ & $(\mathrm{s} . \mathrm{d} .=.40)$ \\
\hline \multirow[t]{6}{*}{$7(2)$} & Low & 2.68 & 2.33 & 2.43 \\
\hline & $\mathrm{n}=8$ & (s.d. $=.98)$ & $($ s.d. $=.97)$ & $(\mathrm{s} . \mathrm{d} .=.92)$ \\
\hline & Mid & 3.01 & 2.92 & $2.99 * \uparrow$ \\
\hline & $n=67$ & $(\mathrm{~s} . \mathrm{d} .=.59)$ & (s.d. $=.58)$ & (s.d. $=.53$ ) \\
\hline & High & 2.98 & $3.22 * \uparrow$ & $3.26^{*} \uparrow$ \\
\hline & $\mathrm{n}=24$ & (s.d. $=.56)$ & $($ s.d. $=.49)$ & $(\mathrm{s} . \mathrm{d} .=.50)$ \\
\hline
\end{tabular}

* Significant at the .05 level 2-tailed, ** significant at the .01 level 2-tailed. $\uparrow$ indicate differences with group above only

Table 6: Mean scores for Sentence Repetition and Photo Description tasks Y5-7

\begin{tabular}{cccc}
\hline Task & Year & Overall Mean \& & Range \\
& & s.d. & \\
\hline Sentence Repetition & 5 & $23.48(9.58)$ & $1-50$ \\
& 6 & $26.78(9.70)$ & $6-49$ \\
& 7 & $30.88(8.89)$ & $8-51$ \\
Photo Description & 5 & $13.91(8.14)$ & $0-39$ \\
& 6 & $16.09(7.78)$ & $0-40$ \\
& 7 & $19.66(8.48)$ & $3-45$ \\
\hline
\end{tabular}


Table 7: Spearman Rank Order correlations between individual variables and task scores Year 5-7

\begin{tabular}{lllll}
\hline & Gender & $\begin{array}{l}\text { L1 Literacy } \\
\text { Level }\end{array}$ & $\begin{array}{l}\text { Attitudes to } \\
\text { learning } \\
\text { French }\end{array}$ & Self-Efficacy \\
\hline Sentence Rep Y5 & $.242^{* *}$ & $.532^{* *}$ & - & - \\
Photo Des Y5 & $.303^{* *}$ & $.591^{* *}$ & - & - \\
Sentence Rep Y6 & $.256^{* *}$ & $.632^{* *}$ & .113 & $.392^{* *}$ \\
Photo Des Y6 & $.248^{* *}$ & $.611^{* *}$ & .096 & $.486^{* *}$ \\
Sentence Rep Y7 & $.251^{* *}$ & $.613^{* *}$ & $.207^{* *}$ & $.438^{* *}$ \\
Photo Des Y7 & $.199^{*}$ & $.591^{* *}$ & $.263^{* *}$ & $.473^{* *}$
\end{tabular}

Table 8: Mean scores and standard deviations for the SR and PD tasks by L1 Literacy level Years 5 to 7

\begin{tabular}{|c|c|c|c|}
\hline $\begin{array}{l}\text { L1 Literacy } \\
\text { level }\end{array}$ & Year & $\begin{array}{c}\text { SR Task mean } \\
\text { Score }(S D)\end{array}$ & $\begin{array}{c}\text { PD Task mean } \\
\text { Score }(S D)\end{array}$ \\
\hline \multirow[t]{6}{*}{ Low } & 5 & 13.96 & 6.14 \\
\hline & $\mathrm{n}=28$ & (s.d.=7.92) & (s.d.=3.32) \\
\hline & 6 & 16.64 & 8.04 \\
\hline & $n=25$ & (s.d.=6.85) & $($ s.d. $=5.23)$ \\
\hline & 7 & 18.86 & 10.07 \\
\hline & $\mathrm{n}=14$ & (s.d.=9.30) & (s.d.=4.87) \\
\hline \multirow[t]{6}{*}{ Mid } & 5 & 23.04 & 13.04 \\
\hline & $\mathrm{n}=171$ & (s.d.=8.49) & (s.d.=6.72) \\
\hline & 6 & 25.85 & 15.33 \\
\hline & $\mathrm{n}=165$ & $($ s.d. $=8.80)$ & (s.d.=6.75) \\
\hline & 7 & 30.20 & 18.64 \\
\hline & $\mathrm{n}=113$ & (s.d.=7.58) & $(7.29)$ \\
\hline \multirow[t]{6}{*}{ High } & 5 & 29.92 & 20.85 \\
\hline & $\mathrm{n}=53$ & (s.d.=9.11) & (s.d.=9.06) \\
\hline & 6 & 34.78 & 22.49 \\
\hline & $\mathrm{n}=102$ & (s.d.=7.49) & (s.d.=7.70) \\
\hline & 7 & 37.51 & 26.41 \\
\hline & $\mathrm{n}=75$ & (s.d.=6.69) & (s.d.=8.10) \\
\hline
\end{tabular}

Table 9: Bonferroni post-hoc comparison between literacy groups

\begin{tabular}{ccc}
\hline Measure & Academic Level & $p$ value \\
\hline SR Task & Low vs Mid & $<.001$ \\
& Mid vs High & $<.001$ \\
& Low vs High & $<.001$ \\
PD Task & Low vs mid & $<.001$ \\
& Mid vs High & $<.001$ \\
& Low vs High & $<.001$
\end{tabular}


Table 10: General linear regression models for SR task Years 5 to 7

\begin{tabular}{|c|c|c|c|c|c|c|c|c|c|c|c|c|}
\hline \multirow[t]{2}{*}{ Variable } & \multicolumn{4}{|c|}{ SR Year 5} & \multicolumn{4}{|l|}{ SR Year 6} & \multicolumn{4}{|l|}{ SR Year 7} \\
\hline & $B$ & $S E B$ & $\beta$ & $t$ & $B$ & $S E B$ & $\beta$ & $t$ & $B$ & $S E B$ & $\beta$ & $t$ \\
\hline L1 Literacy & 2.396 & .281 & .465 & $8.536 * *$ & 2.584 & .266 & .497 & $9.705^{* * *}$ & 2.573 & .313 & .509 & $8.224 * *$ \\
\hline Sch1vsSch2 & -7.997 & 1.872 & -.267 & $-4.272 * *$ & -9.922 & 1.710 & -.335 & $-5.801^{* *}$ & -3.999 & 1.803 & -.171 & $-2.218^{*}$ \\
\hline SchlvsSch 3 & -3.312 & 1.661 & -.137 & $-1.994 *$ & -7.285 & 1.519 & -.305 & $-4.795^{* *}$ & -1.561 & 1.644 & -.078 & -.950 \\
\hline SchlvsSch4 & -10.361 & 2.064 & -.300 & $-5.019 * *$ & -11.929 & 1.874 & -.353 & $-6.367^{* * *}$ & -9.056 & 2.181 & -.269 & $-4.152 * *$ \\
\hline SchlvsSch5 & -5.671 & 2.240 & -.145 & $-2.532^{*}$ & -12.423 & 2.127 & -.297 & $-5.842 * *$ & -8.325 & 2.243 & -.238 & $-3.711 * *$ \\
\hline SchlvsSch6 & -2.367 & 1.922 & -.078 & -1.232 & -8.228 & 1.781 & -.273 & $-4.619^{* *}$ & -4.284 & 3.713 & -.066 & -1.154 \\
\hline SchlvsSch7 & -4.495 & 1.891 & -.148 & $-2.377^{*}$ & $-9.545^{*}$ & 1.782 & -.312 & $-5.356^{* *}$ & -4.886 & 2.089 & -.161 & $-2.339^{*}$ \\
\hline SchlvsSch8 & -8.319 & 1.944 & -.269 & $-4.299 * *$ & -8.482 & 1.777 & -.277 & $-4.774 * *$ & -3.237 & 2.049 & -.112 & -1.580 \\
\hline SchlvsSch 9 & -13.004 & 2.015 & -.339 & $-6.453^{* *}$ & -16.817 & 1.930 & -.486 & $-8.714^{* *}$ & -13.893 & 2.235 & -.413 & $-6.218^{* *}$ \\
\hline Self-efficacy & - & - & - & - & 2.013 & .927 & .127 & $2.172^{*}$ & 2.934 & 1.250 & .169 & $2.347^{*}$ \\
\hline Attitudes to learning & - & - & - & - & .162 & .852 & .010 & .190 & -1.319 & 1.224 & -.068 & -1.078 \\
\hline \multicolumn{13}{|l|}{ French } \\
\hline Gender & 1.270 & .965 & .066 & 1.317 & 1.380 & .868 & .072 & 1.590 & 1.121 & 1.038 & .063 & 1.081 \\
\hline$R^{2}$ & .457 & & & & .603 & & & & .606 & & & \\
\hline Model F statistic & $20.26^{* *}$ & & & & $27.19^{* *}$ & & & & $18.742 * *$ & & & \\
\hline
\end{tabular}

Table 11: General linear regression models for PD task Years 5 to 7

\begin{tabular}{|c|c|c|c|c|c|c|c|c|c|c|c|c|}
\hline \multirow[t]{2}{*}{ Variable } & \multicolumn{4}{|c|}{ PD Year 5} & \multicolumn{4}{|c|}{ PD Year 6} & \multicolumn{4}{|l|}{$P D$ Year 7} \\
\hline & $B$ & $S E B$ & $\beta$ & $t$ & $B$ & $S E B$ & $\beta$ & $t$ & $B$ & $S E B$ & $\beta$ & $t$ \\
\hline L1 Literacy & 2.040 & .221 & .466 & $9.232 * *$ & 1.911 & .216 & .465 & $8.862^{* * *}$ & 2.284 & .302 & .477 & 7.568 ** \\
\hline Sch1vsSch2 & -5.706 & 1.473 & -.224 & $-3.873^{* * *}$ & -6.671 & 1.386 & -.286 & -4.843 ** & -2.859 & 1.739 & -.129 & -1.644 \\
\hline Sch1vsSch3 & -5.672 & 1.307 & -.276 & $-4.339 * *$ & -3.187 & 1.231 & -.169 & $-2.589 * *$ & -2.473 & 1.585 & -.130 & -1.560 \\
\hline SchlvsSch5 & -9.753 & 1.763 & -.293 & $-5.533^{* *}$ & -8.034 & 1.723 & -.246 & $-4.663 * *$ & -6.774 & 2.163 & -.204 & $-3.131 * *$ \\
\hline SchlvsSch6 & -1.966 & 1.513 & -.076 & -1.300 & -3.306 & 1.443 & -.139 & $-2.291^{*}$ & -4.330 & 3.581 & -.070 & -1.209 \\
\hline SchlvsSch7 & .727 & 1.488 & .028 & 489 & -1.481 & 1.444 & -.061 & -1.026 & -5.694 & 2.015 & -.198 & $-2.826^{* *}$ \\
\hline SchlvsSch 8 & -4.655 & 1.530 & -.177 & -3.042 ** & -2.913 & 1.439 & -.120 & $-2.024^{*}$ & -3.813 & 1.976 & -.140 & -1.929 \\
\hline Gender & 2.223 & .759 & .137 & $2.927 * *$ & .995 & .703 & .066 & 1.415 & .367 & 1.001 & .022 & .366 \\
\hline$R^{2}$ & .534 & & & & .584 & & & & .592 & & & \\
\hline Model F statistic & $27.607 * *$ & & & & 25.161 ** & & & & $17.622 * *$ & & & \\
\hline
\end{tabular}

